Article

\title{
Development of a General Protocol to Enhance the Hydrological Analysis Techniques for Urban Catchments in Ireland
}

\author{
Elisa Longo * and John Paul Rooney \\ Roughan \& O'Donovan, Arena House, Arena Road, Sandyford, Dublin 18, D18 V8P6, Ireland; \\ johnpaul.rooney@rod.ie \\ * Correspondence: elisa.longo@rod.ie
}

Received: 30 May 2018; Accepted: 3 July 2018; Published: 9 July 2018

\begin{abstract}
The hydrological analysis of urban catchments is a critical consideration for all major civil engineering projects. The purpose of this article is to develop a general protocol to enhance the established techniques for estimating runoff from Irish urban catchments. The chosen case study is the Rye Water catchment, which is covering two significant urban centres, Maynooth and Leixlip. The findings were compared with the flow data available on the Office of Public Works (OPW) website, to verify the reliability of the proposed approach. The study showed that the methodology described in this paper is applicable to Irish catchments and the protocol, with minor improvements can be adopted in Ireland to support designers in their approach to extreme rainfall events.
\end{abstract}

Keywords: hydrology; rainfall; flow; return period; catchment; flood; analysis; protocol; time of concentration

\section{Introduction}

Floods became a serious topic worldwide in the last ten years. The European Union (EU) issued a number of directives and regulations to face the problem, however, the diversity of climates and coping capacities of the different countries means the adoption of a consistent transnational approach is challenging. European countries accepted the regulations that were proposed by the EU as general guidelines adapting them depending on the population coping capacities, the climate of the country, the differences in terms of legislation, and many other factors.

One of the most relevant documents issued by the European Commission is the Flood Directive (FD) 2007/60/EC [1], which requires the member states:

- to undertake Preliminary Flood Risk Assessments (PFRA);

- to produce Flood Hazard Maps and Flood Risk Maps; and,

- $\quad$ to develop Flood Risk Management Plans.

In order to produce the above-mentioned deliverables a high level of detail is needed, especially for the hydrological analyses. The FD 2007/60/EC does not give any indication regarding the procedure to use to develop the hydrological analysis, leaving the member countries free to follow the most appropriate approach.

Ireland can be considered in the average as regards flood risk data according to Hans de Moel's article "Flood maps in Europe-methods, availability and use" [2].

Despite the good material produced, Irish practitioners complain of the absence of a general procedure to follow in developing their hydrological analyses, particularly in the case of urban catchments. O'Sullivan et al. [3] assessed the difficulties that were encountered in selecting a suitable 
approach to develop hydrological analysis in Ireland. The study, undertaken as part of the Office of Public Works (OPW) Flood Studies Update Programme, comprised both quantitative (posted questionnaires) and qualitative research (focus groups) targeting a range of organisations that are involved in the planning and design of urban drainage infrastructure. This study highlighted, amongst other things, the relatively limited data available, particularly regarding soil parameters.

The main goals of this articles are:

- to develop a general protocol that will be able to help users in developing hydrological analyses of urban catchments; and,

- to compare the data available online and in literature with data estimated through the proposed methodology for two identified catchments.

\section{Materials and Methods}

\subsection{Current Scenario}

Many publications have been issued in order to guide users on the management of the flooding problem before and after any engineering projects. One of the key organisations regarding the Flood Management Strategies is the OPW a leading agency that is aimed to minimize the impacts of flooding through sustainable planning. The most relevant documents that are issued by the OPW in November 2009 are, as follows:

- $\quad$ The Planning System and Flood Risk Management—Guidelines for Planning Authorities [4]

- The Planning System and Flood Risk Management Guidelines for Planning Authorities-Technical Appendices [5]

Both of the documents provide useful information for designers and local authorities to scope all possible impacts on the environment of future developments and indication on how to implement possible mitigation measures to reduce the associated risks.

The OPW has been also active in developing some websites containing flood information, interactive maps, and helpful publications to help end users in developing their hydrological analyses, including the Catchment Flood Risk Assessment and Management (CFRAM) Programme, the Flood Studies Update (FSU) Web Portal, and the Flood Info website.

\subsubsection{The CFRAM Programme}

The CFRAM Programme is a national programme commenced in 2011 and is central to the medium to long-term strategy for the reduction and management of flood risk in Ireland. As part of this programme, a website was released containing all of the information regarding the Catchment Flood Risk Assessment and Management in Ireland.

The Programme delivers on core components of the National Flood Policy [6], adopted in 2004, and on the requirements of the FD 2007/60/EC [1]. The Irish CFRAM programme is being carried out in parallel with similar programmes across the European Union.

OPW works in close partnership with all local authorities in delivering the objectives of the CFRAM Programme. Implementation of the requirements EU Floods Directive is being coordinated with the requirements of the EU Water Framework Directive [7] and the current River Basin Management Plans [8].

According to the objectives set for the CFRAM Programme, the (FD) 2007/60/EC will comprise three stages:

- $\quad$ The Preliminary Flood Risk Assessment (PFRA): 2011

- The CFRAM Studies and parallel activities: 2011-2015

- Implementation and Review: 2016 onwards

The Programme provides for three main consultative stages: 
- 2011 Preliminary Flood Risk Assessments

- 2014 Flood Hazard Mapping

- 2015 Flood Risk Management Plans

\subsubsection{The FSU Web Portal}

The FSU Web Portal is an online website providing design rainfall and flood estimation tools for Ireland.

The FSU Research Programme was commissioned, managed and funded by OPW and is a substantial update of the Flood Studies Report (NERC, 1975) [9], which provided methodologies for flood estimation in Ireland and the United Kingdom. The FSU Web Portal is available for the OPW, local authorities, third level institutions, and private sector practitioners, and it represents a key instrument for professionals working in the area of flood risk assessment and management in Ireland.

\subsubsection{Flood Info}

Flood Info is a recently released website, which was launched on 3 May 2018 and providing access to the published Flood Plans along with the Flood Maps, as developed by the OPW and information about flood risk management in Ireland. The project is part of a more general context, in which the Minister of State Kevin 'Boxer' Moran T.D., in collaboration with the OPW and Flood Relief, published 29 Flood Risk Management Plans to address flood risk in Ireland. The Government has committed almost $€ 1 \mathrm{bn}$ to flood relief measures as part of the National Development Plan 2018-2027 [10].

The main goal of the project is the completion of the largest ever study of flood risk in Ireland and the key outputs of the CFRAM Programme are as follows:

- 40,000 Flood Maps showing the flood risk for 300 communities that support planning decisions and emergency response; and,

- 29 Flood Risk Management Plans to cover the whole country, with the proposed flood relief measures-informed by costs, benefits and environmental factors—-to address the flood risk in each community and nationwide.

Part of the project, has been produced in the report "Implementing the National Flood Risk Policy" [11], published on the website to accompany the publication of the Flood Plans.

Those initiatives, which were promoted mainly by the OPW, seem to sign a mark-up boundary in going towards a new approach of the flood risk management.

On the other side, there is a hidden risk in producing an over-abundance of documents. O'Sullivan et al. [3], after making a ranking the most common used methods (Modified Rational Method, Rational Method and Wallingford Procedure the three most commonly used) provides a clear picture of whose are the greatest difficulties and shortcomings that were encountered by the users in dealing with hydrological analyses, including:

- confidence of methods, inconsistent results, over/underestimates;

- estimation of coefficient of variation, time of concentration and catchment identification

- $\quad$ access to/lack of data (e.g., rainfall);

- lack of guidance or national structured approach; and,

- difficulty in integrating rural and urban catchments.

The emerged trend is not positive considering the number of engineering developments that are influenced by those analyses. The most complained aspect seems to be the lack of a national structured approach, which may help users in choosing the correct path in their professional applications.

A good example of national guidance is represented by "Delivering benefits through evidence-Rainfall runoff management for developments" [12], a report that was published in UK in October 2013 and commissioned by the Environment Agency. The purpose of the report is to provide 
advice to regulators, developers, and local authorities on the management of stormwater drainage for developments and in particular to assist in sizing of storage elements for the control and treatment of stormwater runoff.

The production of a similar document could help Irish users in the future in having only one reference document to follow in dealing with different type of developments. That document would need, in any case, as a starting point, a preliminary research programme to assess the most suitable approach depending on the types of developments.

\subsection{Study Area}

The study area (Figure 1) lies in between County Meath and Kildare, situated in north Leinster, along the east coast of Ireland. The catchments chosen for the study lie along the Rye Water, which rises in County Meath and flows South-East for 19 miles, and it is one of the main tributary of the river Liffey.

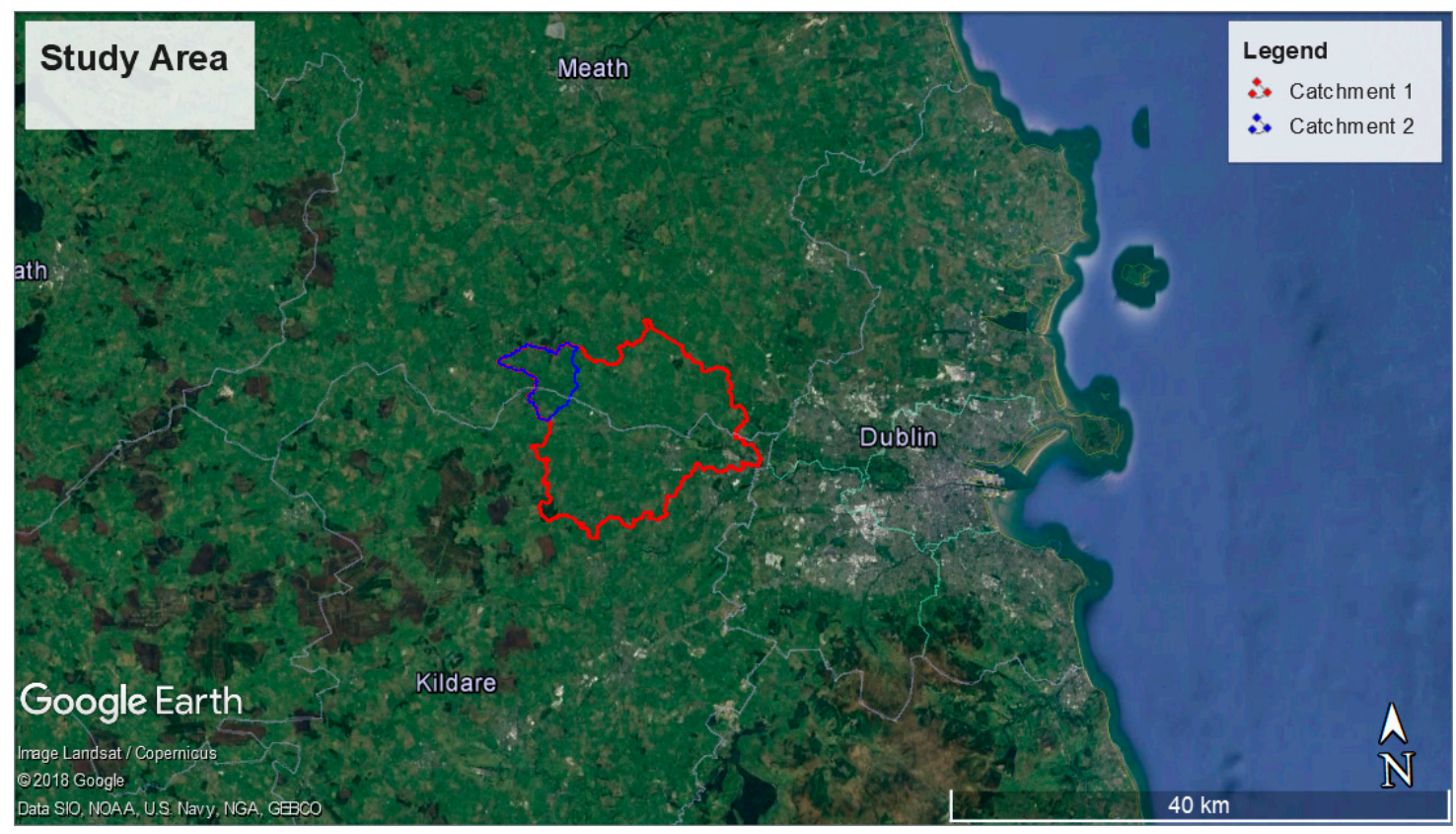

Figure 1. Google Earth view of the study area.

The catchments considered in the research belong both to the Rye Water. The first one, of larger dimensions (200 square Kilometres approximately), named Catchment 1, and a sub-catchment of the first, named Catchment 2 and derived from an upstream closure section of the Rye Water.

\subsection{Proposal Methodology}

The goal of the article was the delineation of a general protocol to simplify the methods that are adopted for the hydrological analyses of Irish urban catchments. The methodology has been applied on two catchments, as mentioned in Section 2.2, Catchment 1, and Catchment 2.

The methodology used to pursue the objective can be summarised in the phases as follows:

1. rainfall data analysis;

2. catchment definition in Geographical Information Systems (GIS);

3. evaluation of the time of concentration; and,

4. flow estimation

These four simple stages can be expanded and detailed, but they give to the users a first idea on how to approach the study of the catchment of interest. 


\subsubsection{Rainfall Data Analysis}

An indirect method was chosen to evaluate the flow for different return periods using rainfall data as input.

The first step was the collection of the rainfall data for the proposed catchment. The purpose of the study was, from the analysis of the historical data of extreme rainfall events, deriving the rainfall depth at $1,3,6,12$, and $24 \mathrm{~h}$ immediately subsequent to the event. The use of this extreme rainfall event data is quite common in Italy, where usually the regional organisation responsible for the collection and the publication of rainfall data also provides the distribution of the rainfall depth at 1, 3, 6, 12, and $24 \mathrm{~h}$ measured at the start of the event. Evidence of the approach can be found in literature in Crisci et al. [13] and Pinto et al. [14].

The challenge, when considering the unavailability of this type of data in Ireland, was the estimation of them starting by historical data available. The information have been supplied by the web portal of Met Eirann, the Irish Metereological Service web portal responsible for monitoring, analysing, and predicting Ireland's weather and climate.

The gauging stations considered relevant for the analysed catchments were initially four:

- Phoenix Park

- Dublin Airport

- Dunsany

- Casement

A gauging station very close to the analysed catchment has been excluded from the analysis because of its lack of hourly rainfall distribution data. The hourly rainfall data in fact were essential to define Peaks Over Threshold (POT) rainfall events for durations of 1, 3, 6, 12, and $24 \mathrm{~h}$.

The first stage was the identification of the daily maximum rainfall depth per year, through the daily distribution, and once identified the day of heaviest rainfall, it was possible to reconstruct the rainfall event through the hourly distribution of the rainfall depth. After cumulating at 1, 3, 6, 12 and $24 \mathrm{~h}$ the rainfall depths, it was possible producing the long series of the rainfall, the values for a number of years variable from 13 to 20 years.

The rainfall depths for 1, 3, 6, 12, and $24 \mathrm{~h}$ were the input for the application of the Generalised Extreme Values (GEV) probability distribution. The intent was the estimation of the Probable Maximum Precipitation and the calculation of the formula describing the temporal distribution of the rainfall depth [15] (p. 137), as follows:

$$
h=a t^{n}
$$

where a represents the rainfall depth of duration one hour and fixed return period and $\mathrm{n}$ is a rainfall factor.

This procedure has been applied to all of the four gauging stations above mentioned.

\subsubsection{Catchment Definition in GIS}

The second important stage was the definition of the catchment and the representation of the stream network in GIS.

The hydrological modelling has been performed in GRASS (Geographic Resources Analysis Support System) GIS, which is commonly referred to as GRASS, a free and open source GIS software suite used for geospatial data management and analysis, image processing, graphics and maps production, spatial modelling, and visualization. The software is part of Quantum GIS Package (QGIS), whicb is a professional GIS application that is built as Free and Open Source Software (FOSS). QGIS has been used in that research for a few conversions of raster and vector files.

The input data elaborated by GRASS was a Digital Elevation Model (DEM) of $30 \mathrm{~m}$ resolution of Ireland, imported in Tiff format and downloaded from the European Environment Agency database. 
The elaboration of the DEM was functional to the representation of the final stream network of the area and the identification of the catchment of interest.

\subsubsection{Evaluation of the Time of Concentration}

Obtained from the shape of the catchment in GRASS, the vector file has been imported in QGIS and the Polygons of Thiessen have been traced to assess how much each gauging station was relevant in terms of rainfall characteristics for the proposed catchments.

In this method, the catchment area is divided into subareas using rain gages as hubs of polygons. The subareas are used to determine ratios that are multiplied by the subarea rainfall and summed to get the catchment average depth. The ratios are the percentages of area in the basin, represented by each rain gage [16].

The result, as shown in Figure 2, has been the exclusion of Dublin Airport and Phoenix Park from the following calculations. The purpose of the polygons of Thiessen, was, in fact, the evaluation of the features of a probable rainfall event within the catchment boundaries; considering that, the only two polygons included within were the ones of Dunsany and Casement their rainfall regimes can be considered as similar to the regime of the catchment. The proportion phase is to quantify how "similar" are these rainfalls. The final product was a temporal distribution of an extreme rainfall event for different return periods, respectful of the effect of each gauging station on the catchment of interest.
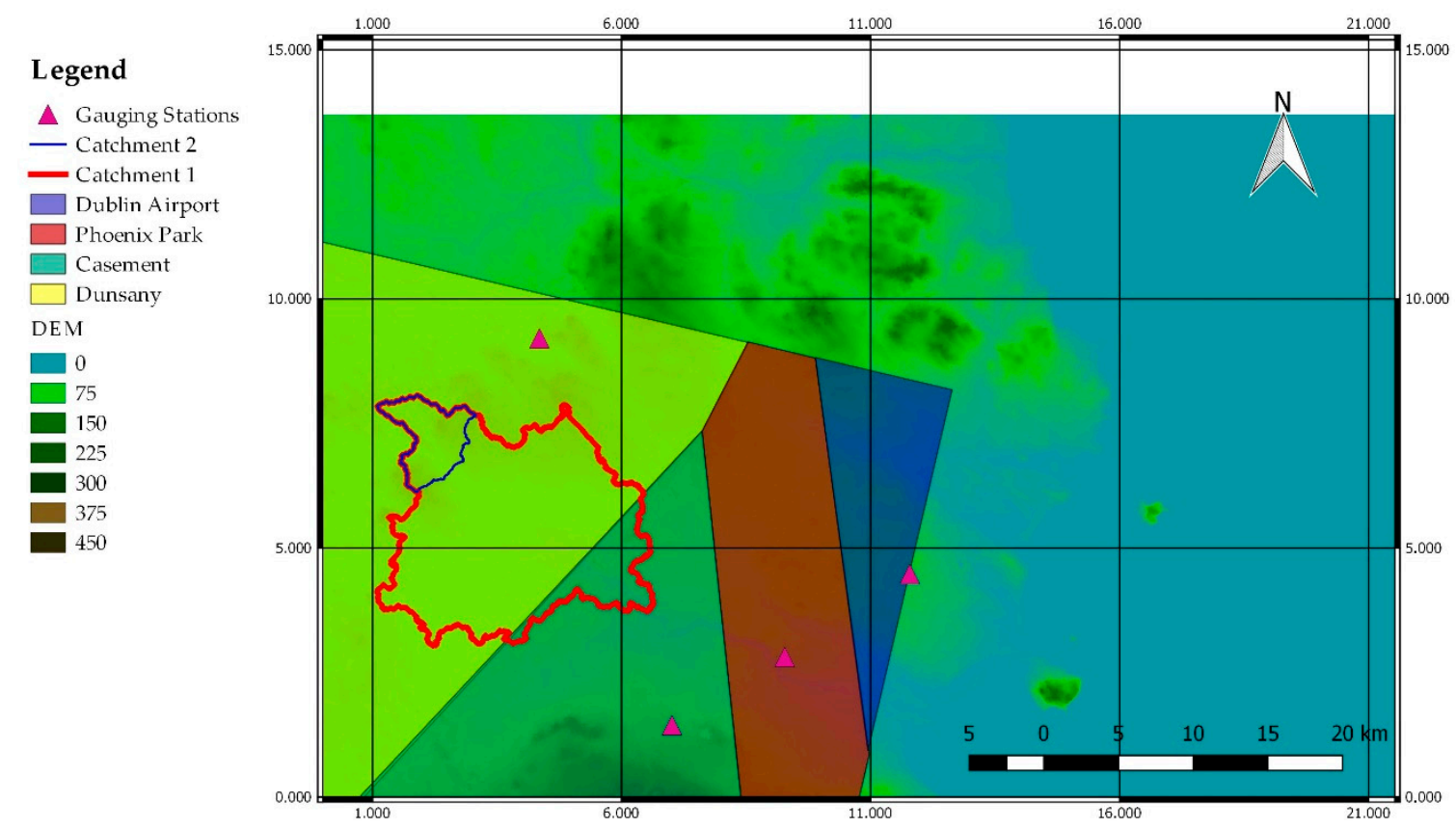

Figure 2. Thiessen Polygons for the Catchment 1 and 2 (image created in Quantum Geographical Information Systems (QGIS)).

It is important specify that the weighting of rainfall data stage was necessary for Catchment 1 only, once Catchment 2 was located in the area of influence of Dunsany, used to progress Phases 3 and 4.

The Polygons of Thiessen procedure was functional to the estimation of the concentration time, the time for a drop of water to flow from the remotest point in the catchment to a closure section of the catchment [17] (p. 499).

The formulas to estimate the concentration time are dependent on the catchment characteristics, and this explains why the catchment definition in GIS has been put as the antecedent stage.

The estimation of the concentration time is a critical task, and considering the empirical nature of formulas that are available in literature, the results obtained have been averaged.

The formulas used are: 
- Kinematic Wave Formulas-Morgali and Linsley (1965) [18] (p. 250)

$$
t_{c}=\frac{\mathrm{L}^{\frac{3}{5}}}{\mathrm{k}_{s}^{\frac{3}{5}} \mathrm{~s}^{\frac{3}{10}} \mathrm{i}^{\frac{2}{5}}}
$$

where

- $\quad$ L is the length of overland flow [m]

- $\quad \mathrm{k}_{S}$ is the Gauckler-Strickler roughness

- $\quad i$ is the rainfall intensity $[\mathrm{m} / \mathrm{s}]$

- $\quad \mathrm{s}$ is the average overland slope $[\mathrm{m} / \mathrm{m}]$

To be solved in $t_{c}$ substituting the intensity with the following equation:

$$
\mathrm{i}=\mathrm{w}_{\mathrm{t}} \mathrm{at} \mathrm{t}_{\mathrm{c}}^{\mathrm{n}-1}
$$

- $\quad$ Kirpich (1940) [18]

$$
t_{c}=0.066\left(\frac{\mathrm{L}}{\sqrt{s}}\right)^{0.77}
$$

where:

- $\quad$ L is the length of channel/ditch from headwater to outlet [Km]

- $\quad \mathrm{s}$ is the average overland slope $[\mathrm{m} / \mathrm{m}]$

- Pezzoli [18]

$$
t_{c}=0.055 \frac{\mathrm{L}}{\sqrt{s}}
$$

where:

- $\mathrm{t}_{\mathrm{c}}[\mathrm{h}]$

- $\quad$ L is the length of overland flow $[\mathrm{Km}]$

- $\quad s$ is the average overland slope $[\mathrm{m} / \mathrm{m}]$

- Giandotti (1934) [18]

$$
\mathrm{t}_{\mathrm{c}}=\frac{4 \sqrt{\mathrm{a}}+1.5 \mathrm{~L}}{0.8 \sqrt{\mathrm{H}}}
$$

where:

- $\quad$ L is the length of overland flow $[\mathrm{Km}]$

- $\quad$ A is the area expressed in $\left[\mathrm{Km}^{2}\right]$

- $\quad \overline{\mathrm{H}}$ is the height of the catchment above the closure section [m]

The formulas that are mentioned are different, however most of them consider the geometric characteristics of the basin as input. The values measured in GRASS were the area, the height of the catchment above the closure section, the length of overland flow, the length of channel/ditch from headwater to outlet, and the average overland slope. The Gauss-Strickler roughness has been derived by values suggested in literature for similar context and the intensity rainfall on the base of the calculations performed in the rainfall data phase.

The value that was obtained with Kirpich equation has been discarded and the remaining values averaged. It was expected that Kirpich formula could provide unreliable values when considering that the equation has been developed from SCS data for seven rural basins in Tennessee with well-defined channel and steep slopes ( $3 \%$ to $10 \%$ ), while the catchments of interest were both quite flat. 


\subsubsection{Flow Estimation Methods}

The methods and formulas used in the third phase of the proposed general protocol have been different for Catchment 1 and Catchment 2, therefore the following sections will be distinguished.

Catchment 1

The methods used to estimate the flow for the Catchment 1 were:

- Soil Conservation Service Curve Number

- Flood Studies Updates Programme

- Rational Method

\section{Soil Conservation Service Curve Number}

The first method used to evaluate the flow has been the Soil Conservation Service Curve Number (SCS-CN), an approach that was widely used as a simple method for predicting direct runoff volume for a given rainfall event [19]. The $\mathrm{CN}$ parameter values corresponding to various soil, land cover, and land management conditions can be selected from tables, but it is preferable to estimate the $\mathrm{CN}$ value from the measured rainfall runoff data if available.

The SCS-CN method is based on the following basic form calculating runoff from rainfall depth,

$$
\begin{gathered}
Q=\frac{\left(P-I_{a}\right)}{P-I_{a}+S} \text { for } P>I_{a} \\
Q=0 \text { for } P \leq I_{a}
\end{gathered}
$$

where

- $\quad P$ is the total rainfall

- $\quad I_{a}$ is the initial abstraction

- $\quad Q$ is the direct runoff

- $\quad S$ is the potential maximum retention

Based on a second assumption, that the amount of initial abstraction is a fraction of the potential maximum retention

$$
I_{a}=\lambda S
$$

Equation (7) becomes

$$
Q=\frac{(P-\lambda S)}{P-\lambda S+S}
$$

The potential retention $S$ is expressed in terms of the dimensionless curve number $(\mathrm{CN})$ through the relationship

$$
S=\frac{1000}{C N}-10
$$

taking values from 0 , when $S \rightarrow \infty$, to 100 , when $S=0$.

This definition was originally applied to the English metric system (with $S$ in inches). In the SI units (with $S$ in $\mathrm{mm}$ ), :

$$
S=\frac{25,400}{C N}-254
$$

According to [20], the Equation (9) has been changed as:

$$
I_{a}=0.2 \mathrm{~S}
$$

The Equation (13) applied to Equation (10) provides:

$$
Q=\frac{(P-0.2 S)}{P+0.8 S}
$$


The input data have been prepared in Excel and the analysis have been performed in HEC-HMS. Flood Studies Update Programme

The second method used was the Flood Studies Update (FSU) through the OPW Hydro NET portal. The portal aims to estimate $Q_{\text {med }}$ in ungauged catchments, or at sites for which there is no data to use or transfer data from a nearby site, which was preferably upstream or downstream from the site of interest. All of the information regarding the theoretical background of the FSU are included in the Final Report-Work Package 2.3 Flood Estimation in Ungauged Catchments [20], developed by the Department of Geography of the Irish Climate Analysis and Research Units (ICARUS) in June 2009.

The use of the FSU was necessary to make a comparison with the data obtained through the SCS-CN. The comparison was helpful, not only to get a first confirmation of the exactness of the delineation of the catchment, but also to calculate a number of flow values of different return periods.

\section{Rational Method}

The rational method [20] has been in use for over 150 years and it remains the most widely used method to estimate peak flows from urban and small rural ungauged catchments [21].

The formula that is used links the peak flow distribution to the catchment area, rainfall intensity $(\mathrm{mm} / \mathrm{h})$, and runoff coefficient, as follows:

$$
Q=C i A
$$

where:

- $Q$ is the peak flow rate $\left[\mathrm{m}^{3} / \mathrm{s}\right]$

- $\quad i$ is the rainfall intensity

- $\quad A$ is catchment, area $\left[\mathrm{Km}^{2}\right]$,

- $\quad C$ is the runoff coefficient

The method is based on the assumptions that rainfall intensity and storm duration are uniform over the area of study. In addition, the other two hypotheses are considered: duration of the storm equal to the time of concentration of the catchment and runoff coefficient constant during a storm [22]. The equation above mentioned must be divided by 360 to work with International System units.

\section{Catchment 2}

For Catchment 2, when considering an area of approximately $20 \mathrm{Km}^{2}$, have been applied three different methods to estimate the flow:

- $\quad \mathrm{IH} 124$

- Flood Studies Updates Programme

- Rational Method

\section{The Institute of Hydrology Report 124}

The Institute of Hydrology Report 124 (IH 124) Report was a research to examine the response of small catchments, less than $25 \mathrm{~km}^{2}$, to rainfall, and to derive an improved flood estimation equation [23]. A total of 84 sites were used to validate the method.

The report worked out also an equation to estimate mean annual flood, QBAR, for small rural and urban catchments: It also worked out an equation to estimate mean annual flood, QBAR, for small rural and urban catchments.

$$
Q B A R_{\text {rural }}=0.00108 \mathrm{AREA}^{0.89} \mathrm{SAAR}^{1.17} \mathrm{SOIL}^{2.17}
$$

\section{Results}

\subsection{Rainfall Data Analysis}

In an Indirect Method the Rainfall Data Analysis stage represents a key phase in describing the rainfall features of a catchment. 
Below have been reported the most relevant tables and charts (Figure 3 and Table 1), according to the theoretical background, as detailed in Section 2.3.1.

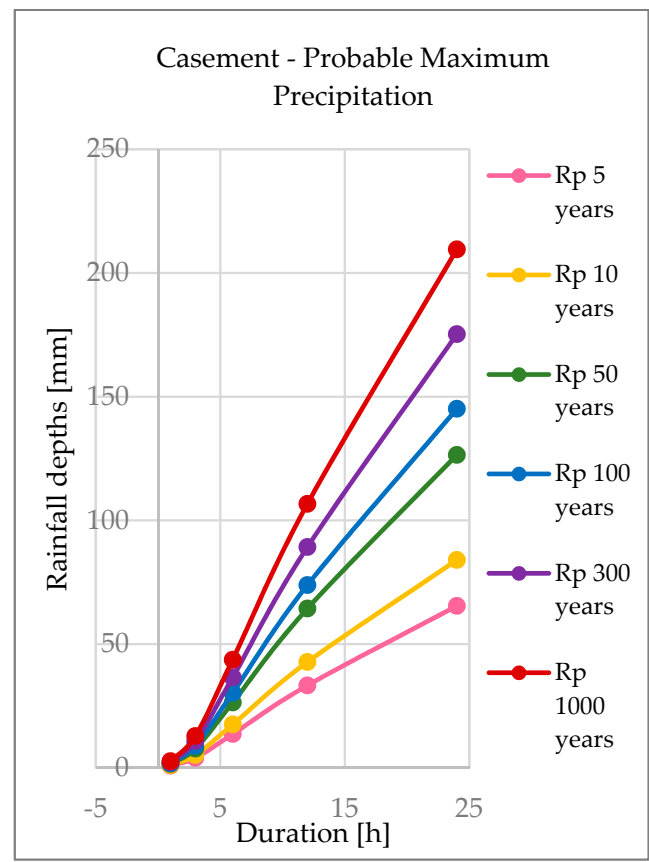

(a)

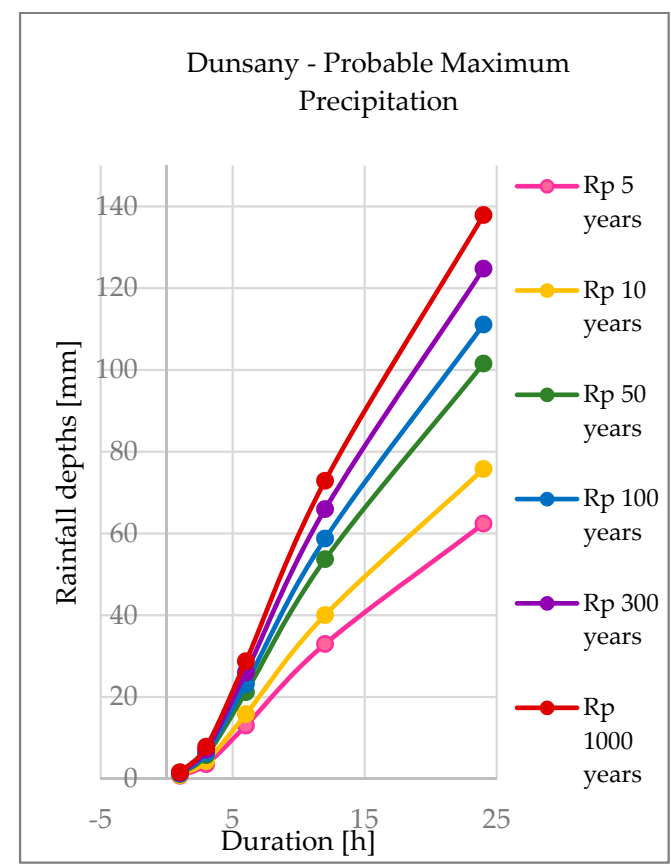

(b)

Figure 3. (a) Probable Maximum Precipitation Curve for the gauging station Casement and (b) Dunsany.

At first sight, it is quite clear how much the two pluviometric regimes are different each other. Casement is in fact characterised by higher rainfall depths, especially for return periods that are above 100 years. On the other hand, Dunsany shows similar values to Casement for rainfall of medium duration (within the six hours) and low return periods (5 to 50 years). We can assume that for small events and not long return period design, approximating one gauging stations with the other could be acceptable. For the purpose of the article and considering that we wanted to be as detailed as we can, we proceeded for Catchment 1 with the Thiessen Polygons.

Below have been listed in Table 1 the value of a and $\mathrm{n}$ for the two gauging stations. The parameters are needed for the formula (1), as presented in Section 2.3.1.

Table 1. Value characteristic of the Probable Maximum Rainfall distribution for Casement and Dunsany.

\begin{tabular}{ccccc}
\hline \multirow{2}{*}{ Return Period (Rp) } & Casement & \multicolumn{2}{c}{ Dunsany } & \\
\cline { 2 - 5 } & $\mathbf{a}$ & $\mathbf{n}$ & $\mathbf{a}$ & $\mathbf{n}$ \\
\hline 5 & 0.78 & & 0.91 & \\
10 & 0.95 & & 1.16 & \\
50 & 1.27 & 1.40 & 1.75 & \\
100 & 1.39 & & 2.01 & \\
300 & 1.56 & & 2.42 & \\
10,000 & 1.72 & & 2.90 & \\
\hline
\end{tabular}

The rainfall data results that were obtained by Casement and Dunsany have been used both for Catchment 1 and Dunsany only for Catchment 2, according to the Thiessen Method, as mentioned in Section 2.3.3. 


\subsection{Catchment Definition in GIS}

The input datum to define the catchment in GRASS has been the $30 \mathrm{~m}$ resolution DEM, downloaded in Tiff format from the European Environment Agency portal, which is an open access website providing DEM to be used for any working use.

The images below enclosed have been produced through the cartographic composer of GRASS and represent some important deliverables in a catchment definition. The process followed to obtain Figure 4, Figure 5a,b and Figure 6a,b can be summarised as follows:

- importing the DEM into the working area;

- $\quad$ sinking the DEM too fill any possible gaps;

- creation of the flow direction raster;

- creation of the flow accumulation raster (the raster calculating the water flowing from the upstream areas into each pixel);

- $\quad$ extraction of the stream network (creating a buffering zone of to the network); and,

- definition of the catchment on the base of the closure section chosen on the network.
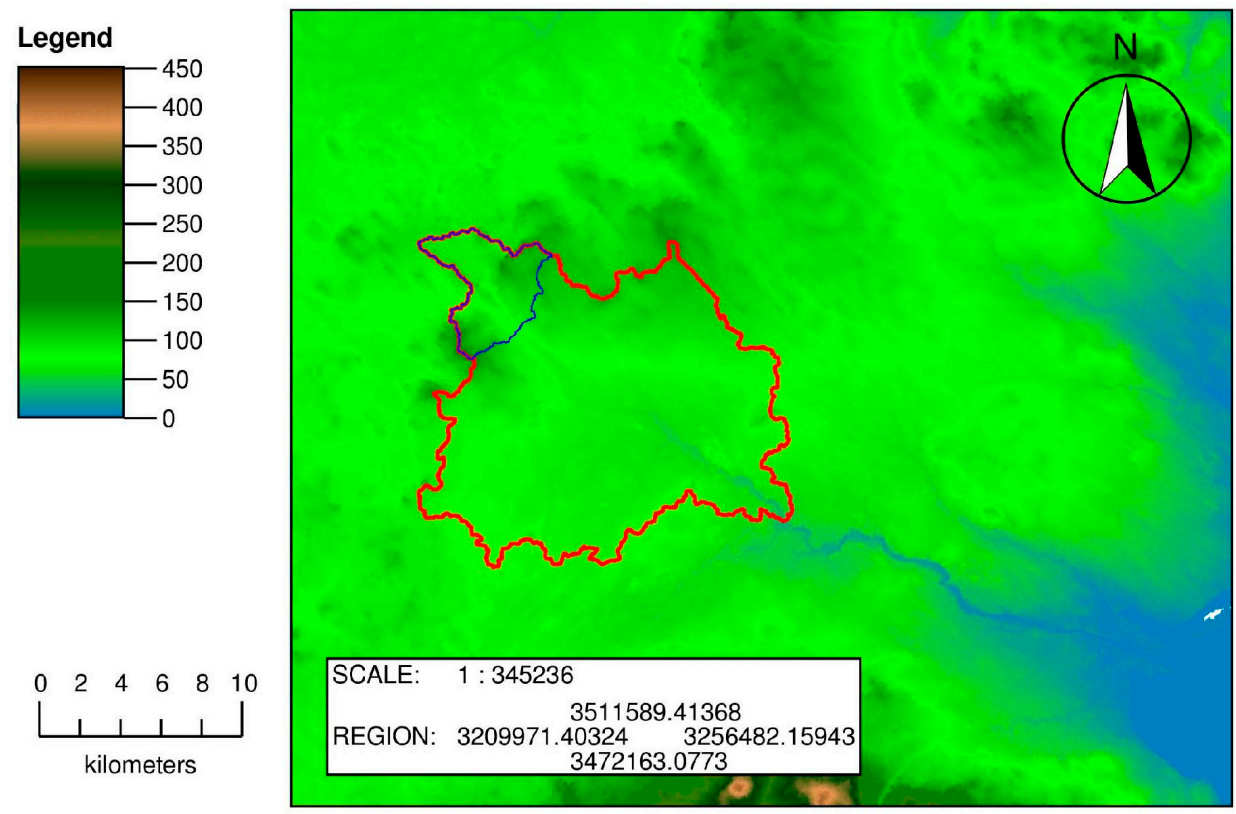

Figure 4. Two-dimensional (2D) Geographic Resources Analysis Support System (GRASS) View of Catchment 1 and 2 visualised on the Digital Elevation Model (DEM).

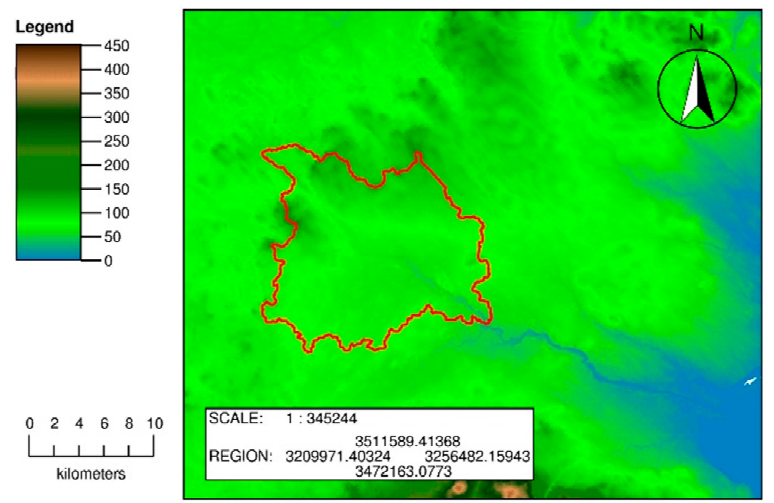

(a)

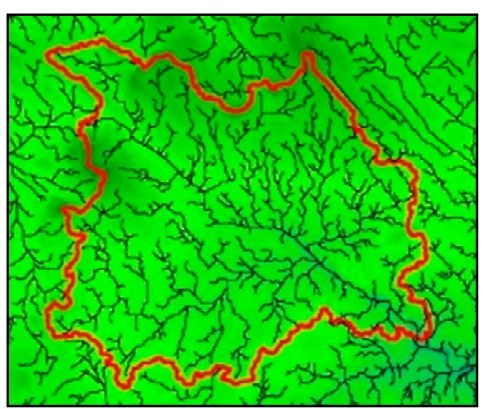

(b)

Figure 5. (a) 2D GRASS View of Catchment 1 visualised on the DEM (b) and showing flow network. 


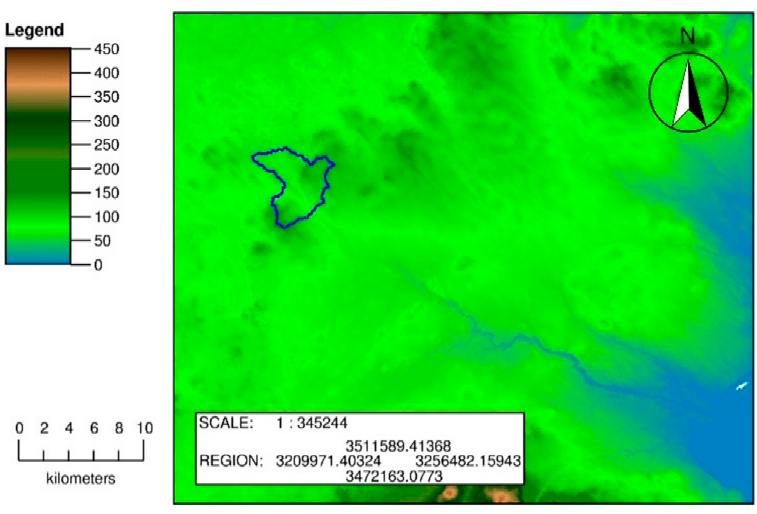

(a)

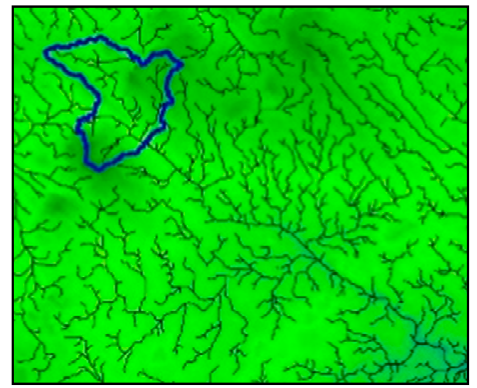

(b)

Figure 6. (a) 2D GRASS View of Catchment 2 visualised on the DEM (b) and showing flow network.

The catchment created can be then converted into a vector file or a $\mathrm{dxf}$ and imported in CAD or in Google Earth. The procedure was applied for both catchments, reiterating the last point for the creation of Catchment 2.

The software GRASS has been very helpful in the catchment definition stage. GRASS is an user friendly software and allows for the creation of a mapset folder where all of the rasters created can be automatically saved during the process. In addition, the software allows for the 3D View of all the raster, including the DEM, a very important tool for professionals working with terrain models.

\subsection{Evaluation of the Time of Concentration}

The four gauging stations that are considered in the Rainfall Data Analysis have been weighted according to the Thiessen Method [16], as explained in detail in Section 2.3.3.

Once evaluated the rainfall parameters for Catchment 1 , and used Dunsany parameters for Catchment 2 , according to the results that were obtained during the second stage, it was possible to then summarise the geometric parameters of the catchments in Table 2 and use them as input for the time of concentration phase.

The formulas used for this stage have been in total four, with one value discarded from the average. It is always good practice to have more than one methods to evaluate the time of concentration, when considering the empirical nature of the formulas and the different measures involved. The procedure was applied separately on Catchment 1 and Catchment 2.

Below listed the main results that were obtained for Catchment 1 and Catchment 2 and the emerged observations.

The great advantage of the first method is the versatility in the evaluation of the time of concentration, function of the return period.

Looking purely at numbers, it can be seen that the time of concentration is approximately halved going from five years return period to 1000 years, a sign that time of concentration and return period are not linked by a close inverse correlation (increasing the return periods 200 times the time of concentration does not become 200 times smaller).

The values obtained through the Giandotti and Pezzoli methods are very similar to the values obtained for five years return period with Morgali and Linsley, therefore, for low scale designs we can assume that those methods would be applicable. In terms of average values, as expected, the highest return period values were the most affected by the use of the additional formulas.

In general, the final values could be considered reliable, when considering the nature of the surface and the dimensions of the catchment, however, it can be appreciated a reduction of time of concentration in the 1000 years return period scenario approximately around the $16 \%$.

The times of concentration obtained have been implemented with the parameters of Table 3 to derive the temporal distribution of the rainfall, which plotted against the return periods provide the curve presented in Figure 7. 
Table 2. Plan Dimensions of Catchment 1 and Catchment 2.

\begin{tabular}{cccccc}
\hline Plan Dimensions & & \multicolumn{2}{c}{ Catchment 1 } & \multicolumn{2}{c}{ Catchment 2 } \\
\hline Area & $\mathrm{A}$ & 204.35 & $\mathrm{Km}^{2}$ & 21.23 & $\mathrm{Km}^{2}$ \\
& $\mathrm{~A}$ & $204,345,359$ & $\mathrm{~m}^{2}$ & $21,225,756$ & $\mathrm{~m}^{2}$ \\
Perimeter & $\mathrm{P}$ & 121.2 & $\mathrm{~m}$ & 34.20 & $\mathrm{~m}$ \\
Length & $\mathrm{L}_{\text {main stream }}$ & 27.1 & $\mathrm{Km}$ & 8.30 & $\mathrm{Km}$ \\
& & 2709 & $\mathrm{~m}$ & 8262 & $\mathrm{~m}$ \\
Main stream maximum height & & 148.1 & $\mathrm{~m}$ & 147.2 & $\mathrm{~m}$ \\
Main stream minimum height & & 35.7 & $\mathrm{~m}$ & 96.5 & $\mathrm{~m}$ \\
Main stream average slope & & 1.9 & $\%$ & 1.5 & $\%$ \\
\hline
\end{tabular}

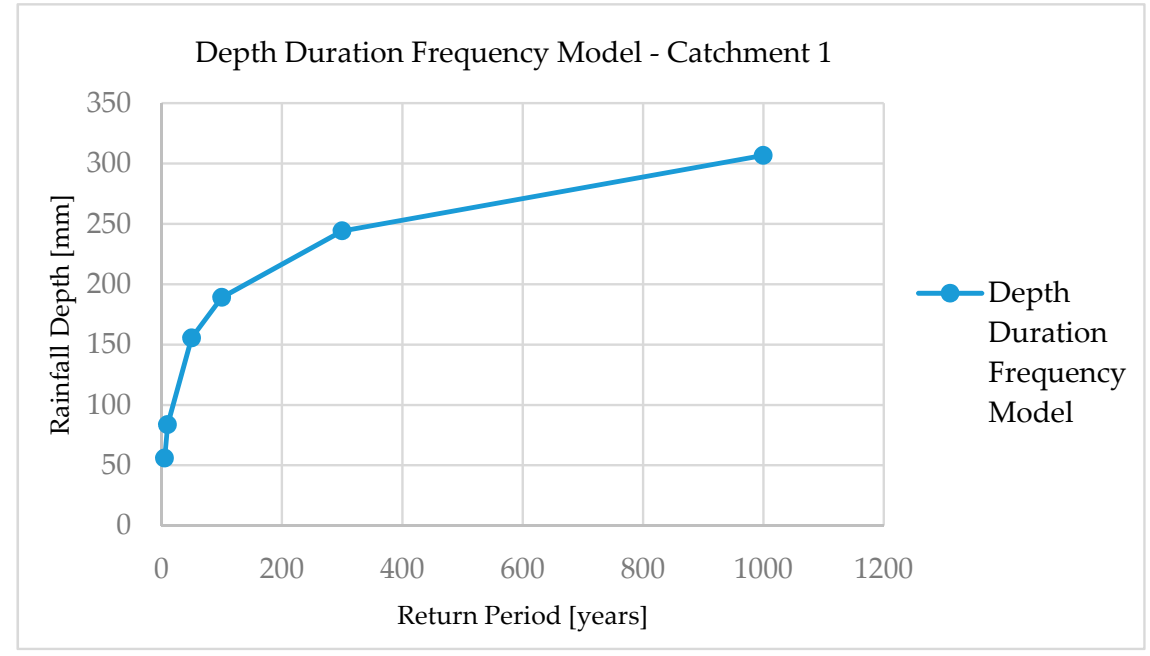

Figure 7. Depth Duration Frequency Model for Catchment 1.

A similar procedure has been applied also to Catchment 2, however, as above-mentioned, the Thiessen Method has been bypassed as initial stage, once the catchment was entirely within Dunsany. The rainfall parameters adopted were therefore the values of Dunsany, as shown in Table 1.

Implementing the plan dimensions of Catchment 2 in the time of concentration formulas have obtained the following results, summarised in Tables 4 and 5 .

In Catchment 2, we can appreciate an inverse trend, comparing Morgali and Linsley and Giandotti and Pezzoli methods, in fact, in that case, the highest return period values obtained through the first method are the most similar to the times that were evaluated with Giandotti and Pezzoli. That relevance lead us to the conclusion that the application of those methods could be well implementable for small catchments and high return periods.

As regards the time of concentration obtained with Kirpich, which is usually applicable to small catchments, we can appreciate an improvement, but not sufficient anyway to promote the value in the average phase, and therefore it has been discarded.

Table 3. Value Characteristic of the catchment weighted between Dunsany and Casement.

\begin{tabular}{cc}
\hline $\mathbf{a}$ & $\mathbf{n}$ \\
\hline 0.76 & \\
0.94 & \\
1.28 & \\
1.41 & 1.44 \\
1.61 & \\
1.79 & \\
\hline
\end{tabular}


Table 4. Estimation of the Time of Concentration Tc for Catchment 1.

\begin{tabular}{|c|c|c|c|c|c|}
\hline \multirow{2}{*}{ Return Period (Rp) ${ }^{1}$} & \multicolumn{5}{|c|}{ Time of Concentration $\left(T_{C}\right)^{1}$} \\
\hline & Morgali and Linsley & Kirpich & Giandotti & Pezzoli & Average \\
\hline 5 & 14.98 & \multirow{6}{*}{4.93} & \multirow{6}{*}{13.91} & \multirow{6}{*}{14.90} & 14.59 \\
\hline 10 & 13.12 & & & & 13.97 \\
\hline 50 & 11.39 & & & & 13.40 \\
\hline 100 & 8.70 & & & & 12.50 \\
\hline 300 & 8.33 & & & & 12.38 \\
\hline 1000 & 8.01 & & & & 12.27 \\
\hline
\end{tabular}

${ }^{1}$ Unit of measurements adopted: Rp [years] Tc [h].

Table 5. Estimation of the Time of Concentration $\mathrm{T}_{\mathrm{c}}$ for Catchment 2.

\begin{tabular}{|c|c|c|c|c|c|}
\hline \multirow{2}{*}{ Return Period $(\mathrm{Rp})^{2}$} & \multicolumn{5}{|c|}{ Time of Concentration $\left(\mathrm{T}_{\mathrm{C}}\right)^{2}$} \\
\hline & Morgali and Linsley & Kirpich & Giandotti & Pezzoli & Average \\
\hline 5 & 8.20 & & & & 5.55 \\
\hline 10 & 7.29 & & & & 5.25 \\
\hline 50 & 6.06 & & & & 4.84 \\
\hline 100 & 5.66 & 1.98 & 3.92 & 4.54 & 4.71 \\
\hline 300 & 5.27 & & & & 4.58 \\
\hline 1000 & 4.95 & & & & 4.47 \\
\hline
\end{tabular}

\subsection{Flow Estimation}

As anticipated in Section 2.3.4, the methods that were applied to evaluate the flow values for Catchment 1 have been different from the methods adopted for Catchment 2, therefore the following sections have been divided.

\subsubsection{Catchment 1}

\section{Soil Conservation Service Method}

The Soil Conservation Service method (SCS-CN) has been applied through Excel to prepare the effective rainfall depth, and the data have been imported in the Hydrologic Modeling System (HEC-HMS) to run the analysis. HEC-HMS is an open source software, as provided by US Army Corps of Engineers, to simulate complete hydrologic processes of watershed systems.

An example of the performed analysis have been reported below in Figures 8 and 9. The unit of measurement used have been years for the return period and $\mathrm{m}^{3} / \mathrm{s}$ for the flow values.

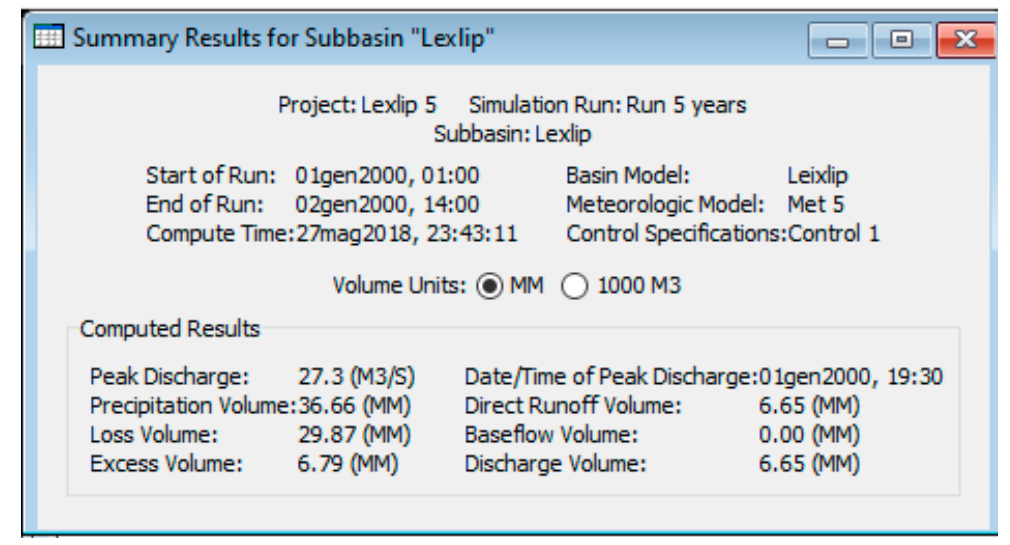

Figure 8. Hydrologic Modeling System (HEC-HMS) Summary Results table obtained for the five years return period scenario. 


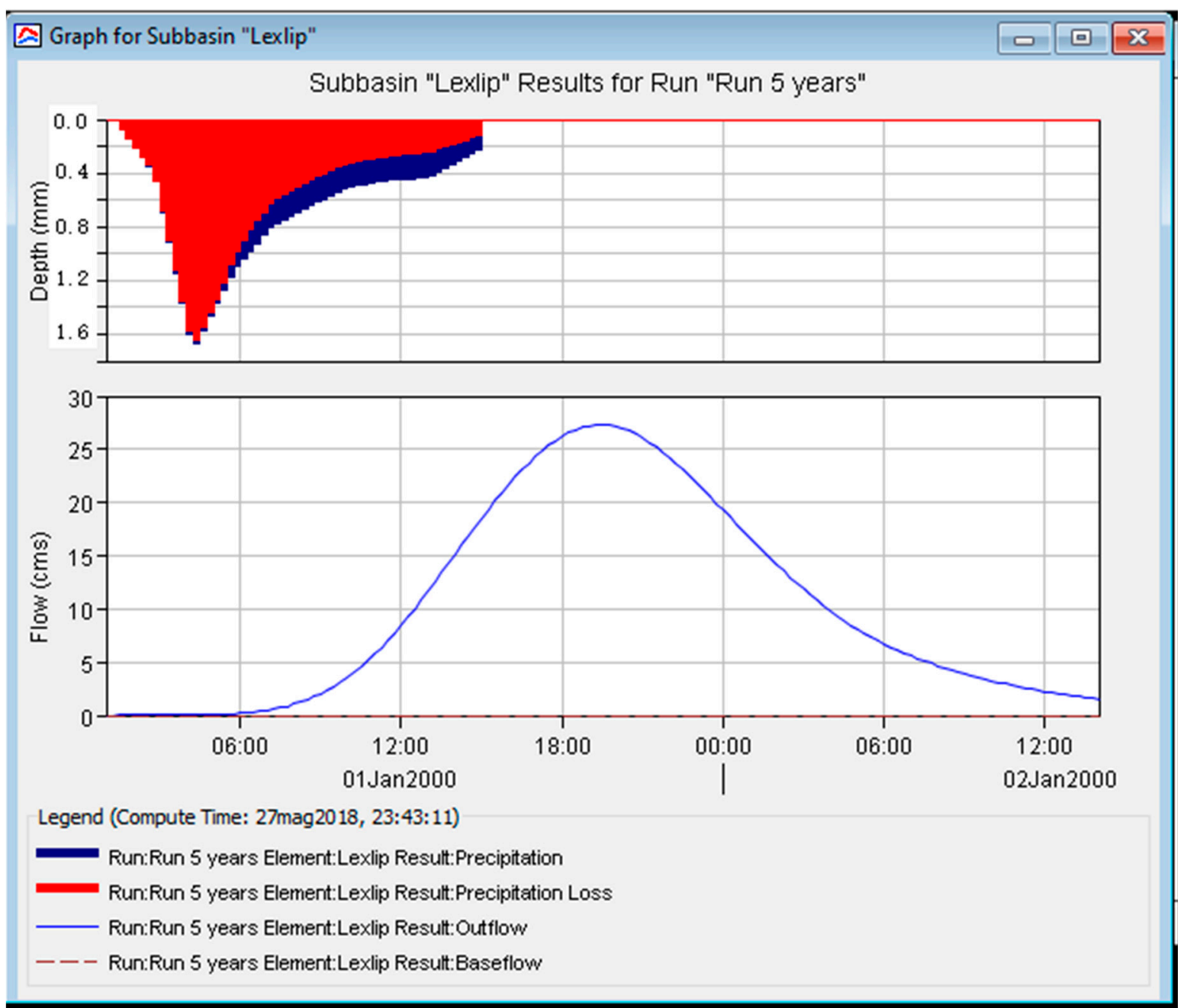

Figure 9. HEC-HMS Summary Graph five years Rp.

The great utility of the software is in particular the possibility to run the model when considering many return period scenarios within the same file, helpful for several analyses running contemporary.

Below have been enclosed a summary table (Table 6) showing all of the values obtained through the SCS-CN Method applied through the HEC-HMS software.

Table 6. Flow values estimated through the Soil Conservation Service Curve Number (SCS-CN) for Catchment 1.

\begin{tabular}{cc}
\hline Return Period $(\mathbf{R p})^{\mathbf{3}}$ & ${\text { Flow }(\mathbf{Q})^{\mathbf{3}}}^{{ }^{\mathbf{3}}}$ \\
\hline 5 & 27.3 \\
10 & 36.6 \\
50 & 66.6 \\
100 & 71.3 \\
300 & 89.9 \\
1000 & 109.8 \\
\hline${ }^{3}$ Unit of measurements adopted: Rp [years] Q $\left[\mathrm{m}^{3} / \mathrm{s}\right]$
\end{tabular}

The flow values obtained with 5 years return period are almost double within the first 50 years return period to reach a flatter shape from 50 to 300 with a low increase until 1000 years return periods.

Flood Studies Update Programme 
The Flood Studies Update Programme offer to its users the possibility to perform a series of rainfall and flood applications, as listed:

- $\quad$ Rainfall Depth Duration Frequency (DDF)

- $\quad$ Flood frequencies

- Hydrograph widths

- Interactive Bridge Invoking the Design Event Method (IBIDEM)

The tool used to perform the analyses has been the "Flood frequencies", which allow for the users on the base of a sequence of options to perform an analysis producing flood values and other flood information.

The stages required by the portal to evaluate the flood values are:

- Identification of the Subject Site

- Choice of a Pivotal Site

- QMED estimation

- $\quad$ Single-Site Flood Frequency Analysis

- $\quad$ Pooled Flood Frequency Analysis

- Review Analysis

Within each section, the designer can pick the most appropriate site and deliver a flood frequency analysis based on a series of input information he should know or decide on the base of the project.

Below included the main deliverables of the flow data estimation through the FSU Programme for Catchment 1 (Figures 10 and 11), as reported in the "Review Analysis".

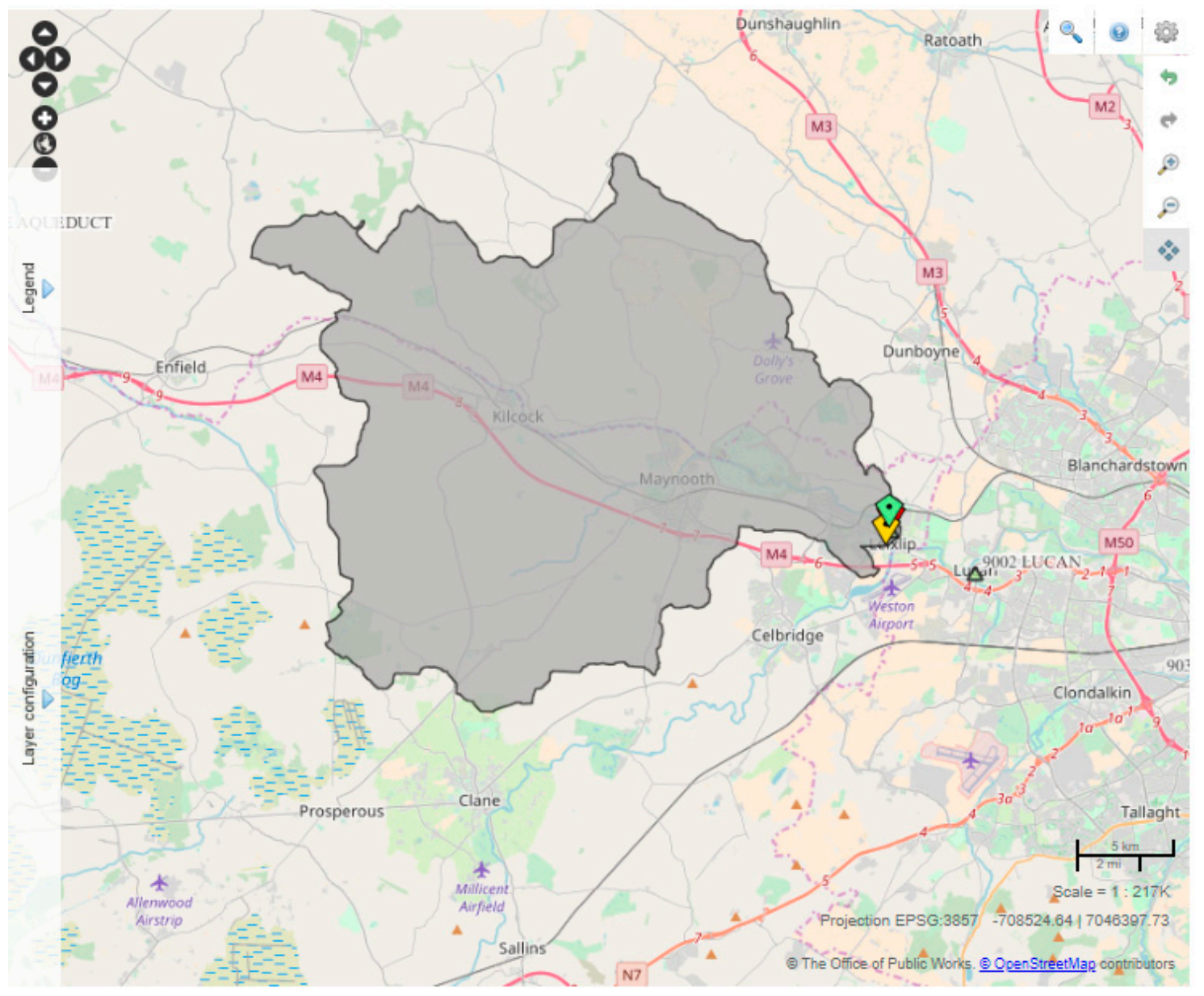

Figure 10. Flood Studies Update (FSU) Web Portal Screen Capture of Catchment 1. 


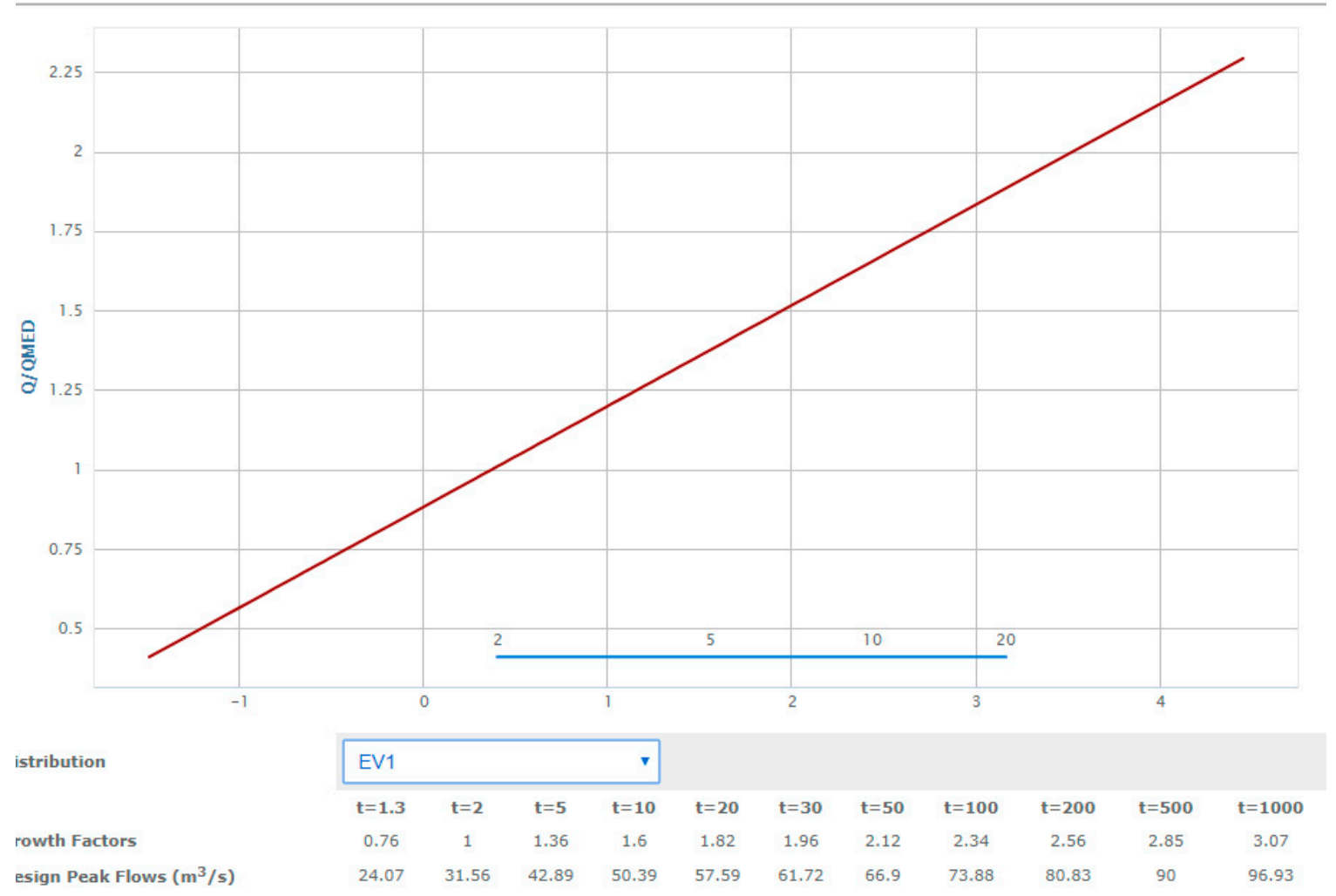

Figure 11. FSU Web Portal Flow Estimation for Catchment 1.

Unfortunately, the OPW portal does not have a dedicated tool for maps creation and downloading a report, which is probably helpful to be added in a future version of the portal.

\section{Rational Method}

The Rational Method is one of the most common used methods worldwide and in Ireland, in particular, according to O'Sullivan et al. [3].

Below included in Table 7 the values obtained through the Rational Method applied on Catchment 1.

Table 7. Flow Values estimated through the Rational Method for Catchment 1.

\begin{tabular}{|c|c|}
\hline Return Period (Rp) ${ }^{4}$ & Flow $(Q)^{4}$ \\
\hline 5 & 24.24 \\
\hline 10 & 36.20 \\
\hline 50 & 66.65 \\
\hline 100 & 71.00 \\
\hline 300 & 90.70 \\
\hline 1000 & 111.70 \\
\hline
\end{tabular}

The flow values obtained are very similar to the ones evaluated through the SCS-CN method. The most important consideration that can be made on the base of what obtained is that it is not important how much sophisticated the calculation method is, if the input values are correct and the method can be considered to be applicable to the catchment of interest, then the result should always be comparable. The results confirmed this hypothesis.

\subsubsection{Catchment 2}

\section{The Institute of Hydrology Report 124}


The first method used for Catchment 2 to estimate the flow values has been the IH124, an often used method in Ireland and United Kingdom (UK) for small catchments. Below included a summary table (Table 8 ) of the results.

Table 8. Flow values estimated through the IH124 Method for Catchment 2.

\begin{tabular}{|c|c|}
\hline Return Period (Rp) ${ }^{5}$ & Flow $(Q)^{5}$ \\
\hline 5 & 5.91 \\
\hline 10 & 6.73 \\
\hline 50 & 7.75 \\
\hline 100 & 8.04 \\
\hline 300 & 8.25 \\
\hline 1000 & 8.53 \\
\hline
\end{tabular}

${ }^{5}$ Unit of measurements adopted: $\operatorname{Rp}$ [years] $\mathrm{Q}\left[\mathrm{m}^{3} / \mathrm{s}\right]$.

At first sight, we can immediately appreciate a general decrease of flow values, when comparing the results with the data obtained for Catchment 1, with reduced variations going from low to high return periods. It can be then made the assumption that for small catchments the dependence on the return period is not as close, as seen for Catchment 1, ten times bigger than Catchment 2.

\section{Flood Studies Update Programme}

The procedure used through the OPW Portal is the same used for Catchment 1, however the results that were obtained are slightly different. Below presented the deliverables that were obtained (Figures 12 and 13) and immediately after the comments related.

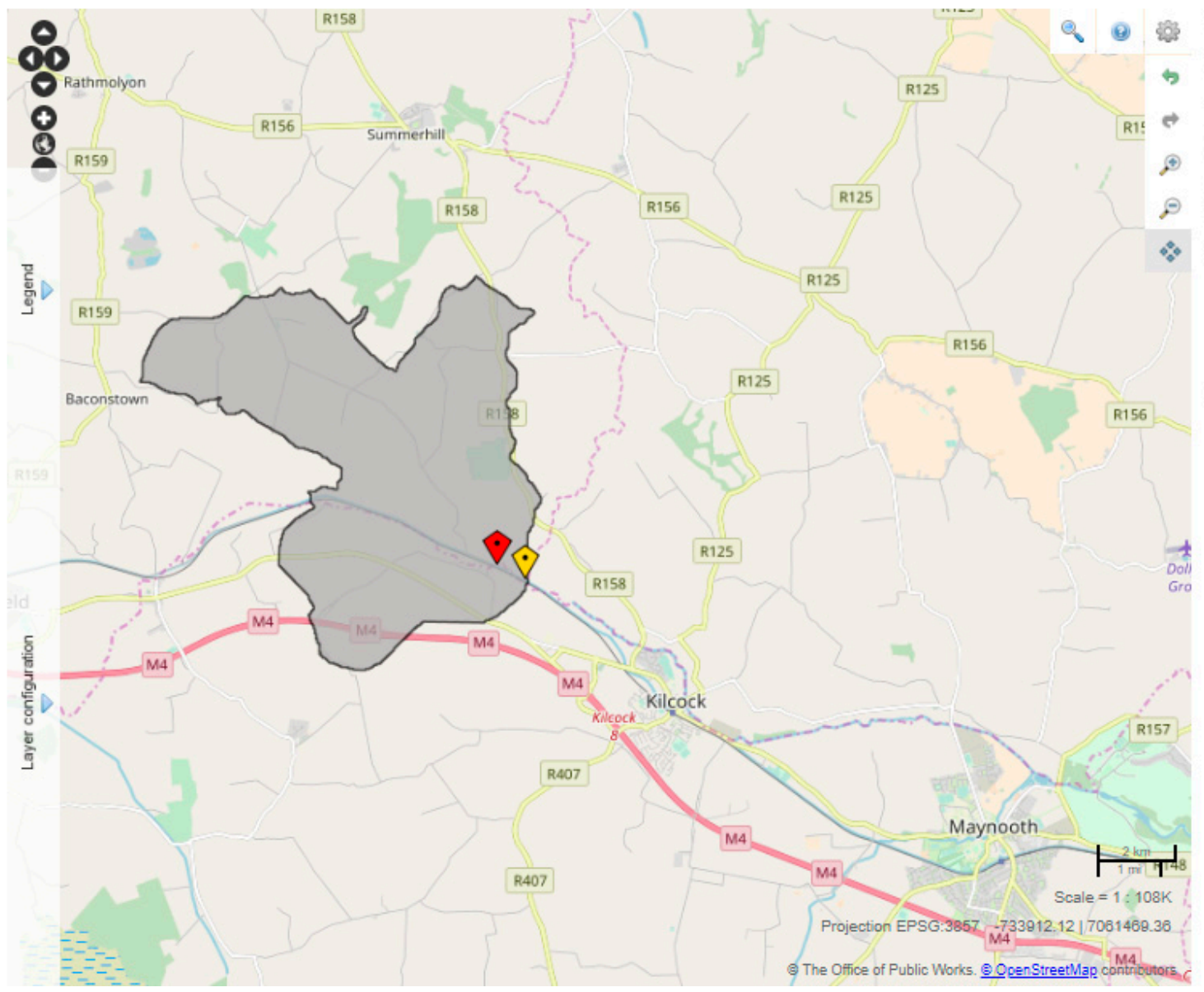

Figure 12. FSU Web Portal Screen Capture of Catchment 2. 


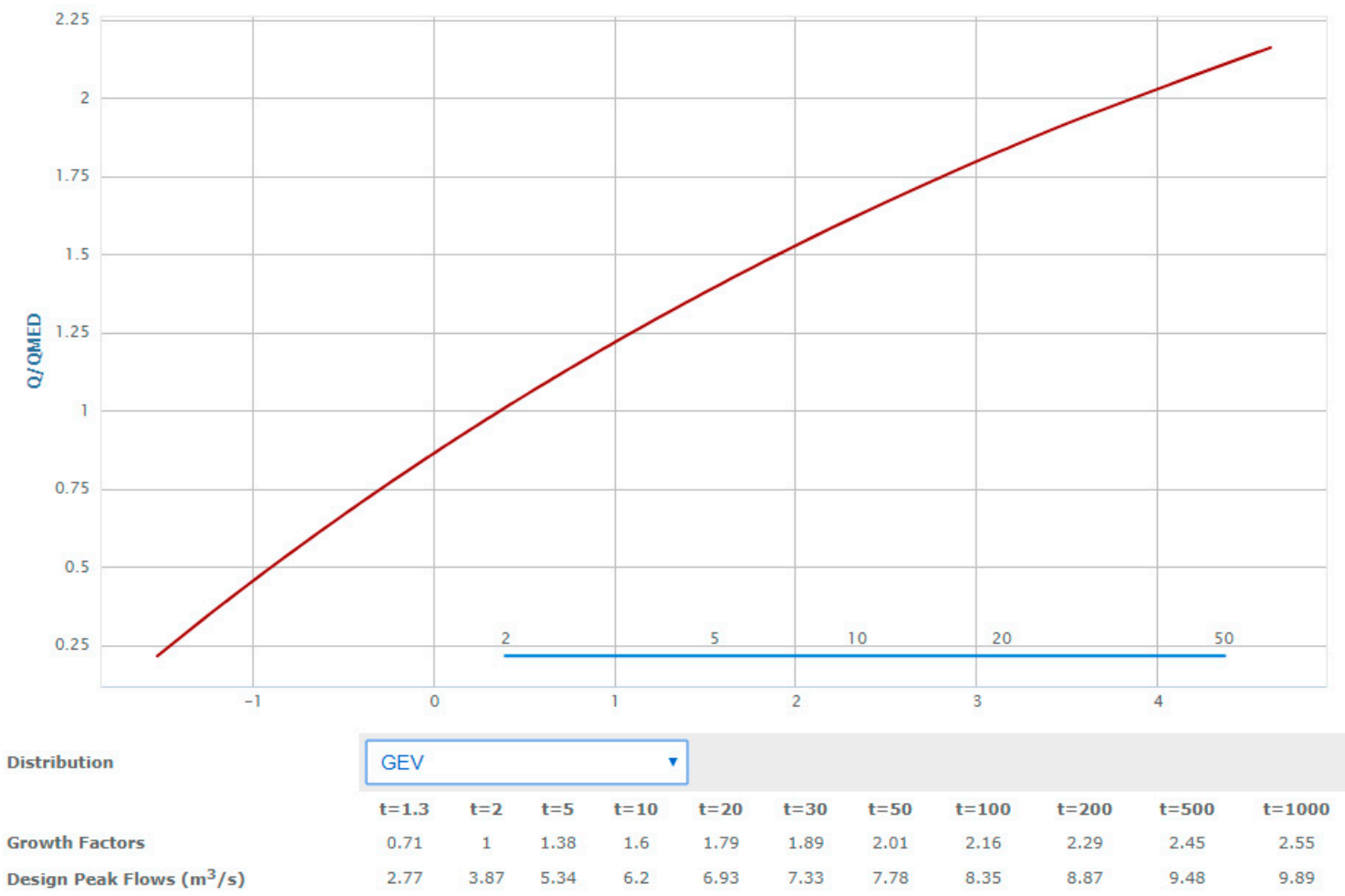

Figure 13. FSU Web Portal Flow Estimation for Catchment 2.

An element worth being mentioned is the slight difference in the shape of Catchment 2, when compared to the one obtained in GRASS. That is probably due to the uncertainty of the OPW model derived for the closure section. The portal approximate, in fact, the catchment using a number of points that are available for users, is therefore very difficult to get exactly the same results in terms of shape

\section{Rational Method}

The rational method is probably for Catchment 2 the method more complete and respectful of the background information provided in phase 1,2, and 3 of the proposed protocol. The results have been listed in Table 9.

Table 9. Flow values estimated through the Rational Method for Catchment 2.

\begin{tabular}{cc}
\hline Return Period (Rp) $^{\mathbf{6}}$ & ${\text { Flow }(\mathbf{Q})^{\mathbf{6}}}^{{ }^{6}}$ \\
\hline 5 & 5.08 \\
10 & 5.62 \\
50 & 6.66 \\
100 & 7.18 \\
300 & 7.65 \\
1000 & 8.11 \\
\hline${ }_{6}$ Unit of measurements adopted: Rp [years] Q $\left[\mathrm{m}^{3} / \mathrm{s}\right]$
\end{tabular}

\section{Discussion and Conclusions}

The findings of the research opened the possibility for users to apply an alternative method to develop hydrological analyses on urban catchments.

The different methods used to estimate flow data for Catchment 1 and 2 provided encouraging results in terms of values.

For Catchment 1, the data obtained have been summarised in Table 10. 
Table 10. Flow data obtained for Catchment 1 through the proposed methods.

\begin{tabular}{cccc}
\hline \multicolumn{4}{c}{ Catchment 1 (Q) ${ }^{7}$} \\
\hline Return Period (Rp) ${ }^{7}$ & SCS-CN & FSU & Rational Method \\
\hline 5 & 27.3 & 42.89 & 24.24 \\
10 & 36.6 & 50.39 & 36.20 \\
50 & 66.6 & 66.9 & 66.65 \\
100 & 71.3 & 73.88 & 71.00 \\
300 & 89.9 & 83.89 & 90.70 \\
1000 & 109.8 & 96.93 & 111.70 \\
\hline \multicolumn{4}{c}{}
\end{tabular}

It is evident that the greatest discrepancy is between the SCS-CN and the FSU method, providing in any case differences in percentage under the $20 \%$ with the two exceptions of flows evaluated for 5 and 10 years return period. The different values could be explained by the size of the catchment, usually in fact, when hydrological analyses are performed for these catchments, the purpose is the designing of an important engineering structure and the return periods of design are above the 30 years. The deriving percentage is therefore acceptable if considered to be that for smaller catchments lower return periods would be chosen.

Looking at Catchment 2, the flow values that were obtained have been listed in Table 11.

Table 11. Flow data obtained for Catchment 2 through the proposed methods.

\begin{tabular}{cccc}
\hline \multicolumn{4}{c}{ Catchment 2 } \\
\hline Return Periods (Rp) ${ }^{8}$ & IH124 & FSU & Rational Method \\
\hline 5 & 5.92 & 5.63 & 5.08 \\
10 & 6.73 & 6.38 & 5.62 \\
50 & 7.76 & 6.91 & 6.66 \\
100 & 8.04 & 7.62 & 7.18 \\
300 & 8.26 & 7.85 & 7.65 \\
1000 & 8.53 & 8.05 & 8.11 \\
\hline
\end{tabular}

The results for Catchment 2 are definitely more similar between the three different methods. In fact, differences in terms of percentage error definitely lower than the $10 \%$ can be appreciated.

The main goal of the article was the creation of a general protocol, and the identified main steps emerged in the analysis have been reported in Figure 14.

\section{RAINFALL DATA \\ ANALYSIS}

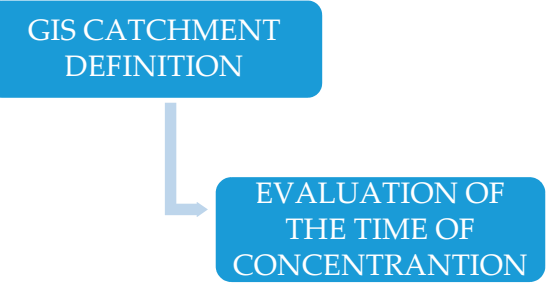

FLOW DATA

ESTIMATION

Figure 14. General Protocol for Hydrological Analyses of Urban Catchments. 
The first element of novelty added to the research has been the different approach to the rainfall data. The attention that was dedicated to the maximum rainfall event within the subsequent $24 \mathrm{~h}$ is in fact very different approach from the use of the Standard Annual Average Rainfall (SAAR) [24], which is one of the most commonly used parameters in Ireland and in UK, which is useful, but at the same time, very generic.

Another element of modernisation proposed in this study has been the shaping of the catchment in GRASS. The creation of the catchment is in fact an important action in any hydrological analysis because it helps the users in understanding the flow network dynamics, but also the real conformation of the ground.

Nevertheless, one of the most innovative element introduced in the research was the application of the SCS-CN method to an Irish catchment. The method has not been used often, probably, when considering the lack of maps showing the Curve Number values for Ireland, however the method proved to be effectively applicable also to Irish catchments. The lack of a $\mathrm{CN}$ map has been solved through the estimation of a reliable value through the Curve Number assessment table [16].

The positive results emerged in the research encourage users in trying the alternative method proposed. The main advantages of the procedure are indeed:

- A more basic and coherent subdivision of the working phases

- A more engaged participation of users in making decisions relevant for their analyses

- A better understanding of the catchment and the rainfall regime characterising it

- A more defined view of the hydrological parameters that shapes the data

- An help for users in becoming critical reviewer of their work

- A different approach to the instruments available in literature and online

The advantages mentioned are an incentive for users and institutions to think about an alternative procedure that is more user friendly and easy to approach.

Key insights for a possible future research could be:

- the assessment of the methods available in literature in order to create a user manual for designers; and,

- the creation of a unified database of information containing high quality data and maps, in particular,

There are, in fact, several applications and GIS map tools that are available online, however the disaggregation of sources and the lack of guidance give the users the perception of being abandoned in the development of their analysis.

In conclusion, the general protocol identified can be represented as a viable alternative procedure to develop hydrological analysis in urban catchments and to support users in dealing with data and resource available in literature and online.

Author Contributions: The choice of the site location, the drafting of the general protocol, the identification of methods and formulas to be used and all the analyses carried on through the different softwares have been performed by E.L. The proposal of performing the analyses on two catchments of different sizes, the use of the Rational Method, a general review of the results and a constant support have been provided by J.P.R.

Funding: The research has been supported by Roughan \& O'Donovan.

Conflicts of Interest: The authors declare no conflict of interest.

\section{References}

1. European Flood Directive. Directive 2007/60/EC of the European Parliament and the Council of 23 October 2007 on the Assessment and Management of Flood Risks; EU: Belgium, Brussels, 2007.

2. De Moel, H.; van Alphen, J.; Aerts, J.C.J.H. Flood maps in Europe-Methods, availability and use. Nat. Hazards Earth Syst. Sci. 2009, 9, 289-301. [CrossRef] 
3. O'Sullivan, J.J.; Gebre, F.; Bruen, M.; Purcell, P.J. An evaluation of urban flood estimation methodologies in Ireland. CIWEN Water Environ. J. 2010, 24, 49-57. [CrossRef]

4. The Planning System and Flood Risk Management-Guidelines for Planning Authorities. OPW: November 2009. Available online: https:/ / www.opw.ie/en/media/Planning\%20Guidelines\%20-\%20FRM\% 20-\%20Nov\%202009.pdf (accessed on 6 July 2018).

5. The Planning System and Flood Risk Management Guidelines for Planning Authorities-Technical Appendices; OPW: November 2009. Available online: https://www.housing.gov.ie/sites/default/files/ migrated-files/en/Publications/DevelopmentandHousing/Planning/FileDownLoad\%2C21709\%2Cen. pdf (accessed on 6 July 2018).

6. National Flood Policy. OPW: September 2004. Available online: https://www.cfram.ie/national-flood-policy / (accessed on 6 July 2018).

7. Water Framework Directive: Directive 2000/60/EC of the European Parliament and of the Council of 23 October 2000 Establishing a Framework for Community Action in the Field of Water Policy; EU: Belgium, Brussels, 2000.

8. River Basin Management Plan 2009-2015; Environment Heritage and Local Government: Dublin, Ireland, 2009.

9. Flood Studies Report (1975), Natural Environment Research Council; 5 Volumes; Director, Institute of Hydrology: Crowmarsh Gilford, UK; Wallingford, UK; Oxfordshire, UK, 2015.

10. National Development Plan 2018-2027 Project Ireland 2040; Government of Ireland: Dublin, Ireland, 2017.

11. Implementing the National Flood Risk Policy Report on Measures in Place and Proposed to Address Ireland's Flood Risk. OPW: May 2018. Available online: https://www.floodinfo.ie/static/floodmaps/docs/key_ messges_page/Implementing_the_Gov_Nat_Flood_Risk_Policy_WEB.pdf (accessed on 6 July 2018).

12. Delivering Benefits through Evidence-Department for Environment, Food and Rural Affairs; Environment Agency: Bristol, UK, 2013; ISBN 978-1-84911-309-0.

13. Crisci, A.; Gozzini, B.; Meneguzzo, F.; Pagliara, S.; Maracchi, G. Extreme rainfall in a changing climate: Regional analysis and hydrological implications in Tuscany. Hydrol. Process. 2002, 16, 1261-1274. [CrossRef]

14. Pinto, J.G.; Ulbrich, S.; Parodi, A.; Rudari, R.; Boni, G.; Ulbrich, U. Identification and ranking of extraordinary rainfall events over northwest Italy: The role of Atlantic moisture. J. Geophys. Res. 2013, 118, 2085-2097. [CrossRef]

15. Ferro, V. La Sistemazione dei Bacini Idrografici; The McGraw-Hill Company: New York, NY, USA, 2002.

16. Storm Rainfall Depth and Distribution. In Hydrology National Engineering Handbook; United States Department of Agriculture Natural Resources Conservation Service: Washington, DC, USA, 2015; Part 630, Chapter 4.

17. Chow, V.T.; Maidment, D.R.; Mays, L.W. Applied Hydrology; McGraw-Hill Civil Engineering; McGraw-Hill: New York, NY, USA, 1949.

18. Grimaldi, S.; Petroselli, A.; Nardi, F.; Tauro, F. Analisi critica dei metodi di stima del tempo di corrivazione. In Proceedings of the XXXII Convegno Nazionale di Idraulica e Costruzioni Idrauliche, Palermo, Italy, 14-17 September 2010.

19. Santo, A.; Santangelo, N.; Beneduce, A.; Iovane, F. Pericolosità connessa ai processi alluvionali in aree pedemontane: Il caso di Castellamare di Stabia in Penisola sorrentina. Italian J. Quat. Sci. 2002, 15, $23-27$.

20. Soulis, K.X.; Valiantzas, J.D. SCS-CN parameter determination using rainfall-runoff data in heterogeneous watersheds-The two-CN system approach. Hydrol. Earth Syst. Sci. 2012, 16, 1001-1015. [CrossRef]

21. Flood Studies Update Programme, Work Package 4.2 Flood Estimation in Small and Urbanised Catchments; Draft 30 January 2012; Hydrology and Coastal Section Engineering Services, OPW: San Francisco, CA, USA, 2012.

22. Flood Studies Update Programme, Work Package 2.3 Flood Estimation in Ungauged Catchments Final Report; Irish Climate Analysis and Research Units (ICARUS) Department of Geography NUI: Maynooth, Ireland, June 2009.

23. Hays, D.C.; Young, R.L. Comparison of Peak Discharge and Runoff Characteristic Estimates from the Rational Method to Field Observations for Small Basins in Central Virginia; USGS Scientific Investigations Report; USGS: Reston, VA, USA, 2003; pp. 2005-5254.

24. Marshall, D.C.W.; Bayliss, A.C. Report No. 124 Flood Estimation for Small Catchments; Institute of Hydrology: Lancaster, UK, 1994.

(C) 2018 by the authors. Licensee MDPI, Basel, Switzerland. This article is an open access article distributed under the terms and conditions of the Creative Commons Attribution (CC BY) license (http:/ / creativecommons.org/licenses/by/4.0/). 